\title{
Information Service for Wheelchair Users
}

\author{
Noriko FUKASAWA \\ Assistant Senior Researcher, \\ Hiroshi MATSUBARA \\ Senior Researcher, \\ Koichi GOTO \\ Passenger Information Systems G., Transport Information Technology Div.
}

There are a number of barriers for wheelchair users travelling by train. Due to this disadvantage, they need more information than non-handicapped people. Nevertheless, they have restraint in obtaining the information to ensure safe travel. It is required, therefore, not only to eliminate physical barriers at stations and on trains, but also to offer high-quality information to compensate for the insufficient railway facilities that are still at improvement stages. To solve the problems in the current information services, the technique proposed in this paper uses Internet and animations to guide wheelchair travelers. It enables as many wheelchair users as possible to easily obtain the information they need and intuitively understand its contents.

Keywords : passenger services, barrier-free, wheelchair users, Internet

\section{Introduction}

In November 2000, the law for transportation accessibility improvement was enforced in Japan. In order to improve the convenience and safety of public transportation for the aged and disabled, the law requires that public transportation operators improve the accessibility of their passenger facilities and vehicles, etc., and set up a framework for concentrated and integrated improvement of passenger facilities, roads, and station squares.

Because there are a number of barriers for wheelchair users at stations and on trains, they need more information to ensure safe travel than non-handicapped people. Nevertheless, they are confused due to the lack of accessibility information about the usage of railway. Wheelchair users restrained from moving, have another restraint to obtain the information. In order to promote the convenience and safety of railway for wheelchair users, it is required not only to eliminate physical barriers at stations and on trains, but also to offer high-quality information for eliminating barriers on information.

In this paper, we will introduce the present state of wheelchair users about collecting information for travelling by train. In order to guide wheelchair travelers more conveniently, we will also propose a new technique using the Internet and personal computers, which attract attention as new tools for wheelchair users to collect information without moving.

\section{Traveling by train for wheelchair users}

\subsection{Transportation of wheelchair users}

According to a report of the Ministry of Health and Welfare in 1996 , on 167.5 million physically disabled people, there are 736 thousand people having supportive devices. Among them, 430 thousand have canes to assist their walking; 300 thousand have manual control wheelchairs and 35 thousand have electric control wheel- chairs (In this investigation, the respondents were allowed to give two or more replies). Some electric control wheelchair users have a handicap not only at the lower part of the body but also at the upper part. Moreover, there are quite a few people who have speech disorders. In this case, they have restraint to communicate in addition to that for moving.

There is a difference in their frequencies of going out and using transportation depending on whether they use a wheelchair or not. Generally, the heavier their handicaps are, the lower their frequencies of going out become. They also have a tendency not to use public transport systems, but to use a personal transportation means. The main reasons for this fact are as follows. Consideration is not given much to wheelchair users regarding the facilities at stations and on trains. Moreover, it is difficult for them to obtain the information on the location of these facilities, how to use them and so on, even if the facilities for wheelchair users have already been installed.

\subsection{Information needed by wheelchair users}

Recently, a number of facilities to support the movement of passengers in stations, such as elevators, escalators and lifts to go up and down stairs are provided. However, they are insufficient for the travel of wheelchair users, because the introduction of these facilities are still at an early stage and not enough in quality and quantity. Therefore, wheelchair users must gather all the information to move from the station entrance to their destination and understand how to use them by searching the latest information. If the information they have obtained is wrong, they will be confused and have troubles when travelling.

We have made an investigation through a private supporting organization for the disabled, to know what kinds of information wheelchair users need. The results of the investigation indicate that wheelchair users need the information on the following. 
(1) Information about routes and facilities at stations

- Physical barriers that block the paths of wheelchair users.

- Facilities such as elevators, escalators, lifts to go up and down stairs, rest rooms for wheelchair users.

- Facilities in the buildings next to the station.

(2) Information about tickets

- Reduced fare tickets for the disabled and how to buy them.

- Ticket gates that can be used by wheelchair users.

(3) Information about platforms

- Dangerous zones for wheelchair users such as a slant on the platform down into the direction of the track.

- Step and gap between a train and a platform.

(4) Information about vehicles

- Steps and widths of train doors.

- Seats and space for wheelchair users.

- Rest rooms for wheelchair users.

(5) Information about services of station staffs

- How to make contact with station staffs.

- Telephone numbers and fax machine numbers of the station.

- Whether wheelchair users must report to station staffs beforehand.

- Time when wheelchair users can easily access the station.

- Station which wheelchair users can easily access.

\section{Actual situation of providing information}

Wheelchair users obtain the information for travelling by train from railway operators, public organizations such as municipal governments and social welfare associations, volunteer groups and organizations for the disabled. When they search the information, there are the following troubles.

- They must make inquiry several times because the information on the objective is dispersed.

- Different station staffs sometimes answer differently at the same station.

- The information in guidebooks and public relations magazines of railway companies sometimes does not

Table 1 Information provided by railway operators (among 104 operators including branch offices)

\begin{tabular}{|l|l|c|}
\hline \multirow{2}{*}{ Contents } & $\begin{array}{c}\text { Number } \\
\text { of railway } \\
\text { operators }\end{array}$ \\
\hline \hline Fare & Reduced fare ticket for disabled & 2 \\
\hline \multirow{3}{*}{$\begin{array}{c}\text { Facility } \\
\text { station }\end{array}$} & Elevator & 14 \\
\cline { 2 - 3 } & Slope & 6 \\
\cline { 2 - 3 } & Escalator & 10 \\
\cline { 2 - 3 } & Escalator for wheelchair users & 3 \\
\cline { 2 - 3 } & Lift to go up and down stairs & 5 \\
\cline { 2 - 3 } & Rest room for wheelchair users & 11 \\
\hline \multirow{3}{*}{$\begin{array}{c}\text { Facility } \\
\text { on a train }\end{array}$} & Space for wheelchair users & 2 \\
\cline { 2 - 3 } & Rest room for wheelchair uses & 2 \\
\hline
\end{tabular}

reflect the actual situation, because it is compiled according to the situation at the time of publication or there are temporary changes.

\subsection{Information provided by railway operators}

The principal ways for railway operators to provide information are categorized as follows.

(1) Public relations magazines

Most railway operators publish their public relations magazines, usually once a month. They contain the information about landmarks along the railway lines, events, time tables and so on. In some magazines, they provide maps of station buildings and the information about facilities for the disabled. These are also useful for wheelchair users.

(2) Booklets for wheelchair users

Some railway operators publish booklets for wheelchair users. Booklets are highly estimated, because they provide the information about the routes for wheelchairs at stations.

(3) Internet

At present, most railway operators have their own Web page on the Internet. However, most of the information provided by the Web pages is only to introduce the company. According to the investigation of Web page of 104 railway operators including branch offices, 20 operators provide information for the convenience of passengers and 15 provide for the convenience of wheelchair passengers (Table 1). However, most of them provide only tables showing whether there are facilities for wheelchair users at each station, or station maps showing the locations of facilities for wheelchair users. Table 2 shows an example of Web pages provided by a railway operator. Among these Web pages, the railway operator provides routes in stations for wheelchair users. The Web

Table 2 Example of page provided by railway operators

\begin{tabular}{|c|c|c|c|c|c|c|}
\hline & \begin{tabular}{|c|}
$\begin{array}{c}\text { Escalator } \\
\text { for } \\
\text { wheelchair } \\
\text { users }\end{array}$ \\
\end{tabular} & Elevator & \begin{tabular}{|c|} 
Rest room \\
for \\
wheelchair \\
users
\end{tabular} & Slope & $\begin{array}{c}\text { Lift to go } \\
\text { up and } \\
\text { down } \\
\text { stairs } \\
\end{array}$ \\
\hline \multirow[t]{10}{*}{ Line A } & a sta. & 0 & 0 & 0 & 0 & - \\
\hline & b sta. & - & - & - & - & - \\
\hline & c sta. & - & - & 0 & - & - \\
\hline & d sta. & - & - & 0 & - & - \\
\hline & e sta. & 0 & - & - & - & - \\
\hline & f sta. & - & - & 0 & 0 & - \\
\hline & g sta. & - & - & - & - & - \\
\hline & h sta. & - & - & 0 & 0 & - \\
\hline & i sta. & - & - & - & - & - \\
\hline & j sta. & 0 & - & - & - & - \\
\hline \multirow[t]{6}{*}{ Line B } & k sta. & 0 & 0 & - & - & - \\
\hline & 1 sta. & 0 & 0 & 0 & - & - \\
\hline & m sta. & 0 & 0 & 0 & - & - \\
\hline & n sta. & 0 & - & 0 & - & 0 \\
\hline & o sta. & - & - & - & 0 & - \\
\hline & p sta. & 0 & 0 & 0 & - & - \\
\hline
\end{tabular}




\begin{tabular}{|c|c|c|}
\hline A station & 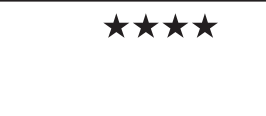 & $\begin{array}{r}\text { 1-1-1, Marunouchi, } \\
\text { Chiyoda-ku } \\
\text { TEL:03-3333-1111 }\end{array}$ \\
\hline $\begin{array}{l}\text { from the entrance } \\
\text { to the ticket gate }\end{array}$ & $\begin{array}{l}\text { around the ticket } \\
\text { gate }\end{array}$ & \multirow[t]{2}{*}{$\begin{array}{l}\text { Ticket gate: } \\
\text { on the ground }\end{array}$} \\
\hline$w^{\circ}$ & $\begin{array}{c}\text { Marunouchi } \\
\text { east } \\
\text { entrance }\end{array}$ & \\
\hline \multicolumn{3}{|c|}{ form the ticket gate to the platform } \\
\hline $\begin{array}{l}\uparrow \downarrow \\
5 \\
\end{array}$ & $\Delta$ & $\begin{array}{l}\uparrow \downarrow \\
5\end{array}$ \\
\hline
\end{tabular}

\begin{tabular}{|c|c|c|}
\hline B station & 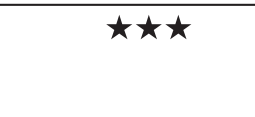 & $\begin{array}{r}\text { 3-3-3, Shinjuku, } \\
\text { Shinjuku-ku } \\
\text { TEL:03-3333-3333 }\end{array}$ \\
\hline $\begin{array}{l}\text { from the entrance } \\
\text { to the ticket gate }\end{array}$ & $\begin{array}{l}\text { around the ticket } \\
\text { gate }\end{array}$ & \multirow{2}{*}{$\begin{array}{l}\text { Ticket gate: } \\
\text { on the ground } \\
\text { Platform: } \\
\text { on the ground }\end{array}$} \\
\hline $\begin{array}{l}1 \downarrow \\
51 \\
51\end{array}$ & $\begin{array}{c}\text { East } \\
\text { entrance }\end{array}$ & \\
\hline \multicolumn{3}{|c|}{ form the ticket gate to the platform } \\
\hline E.p & $\Delta$ & b.p \\
\hline
\end{tabular}

Fig. 1 Example of guide book

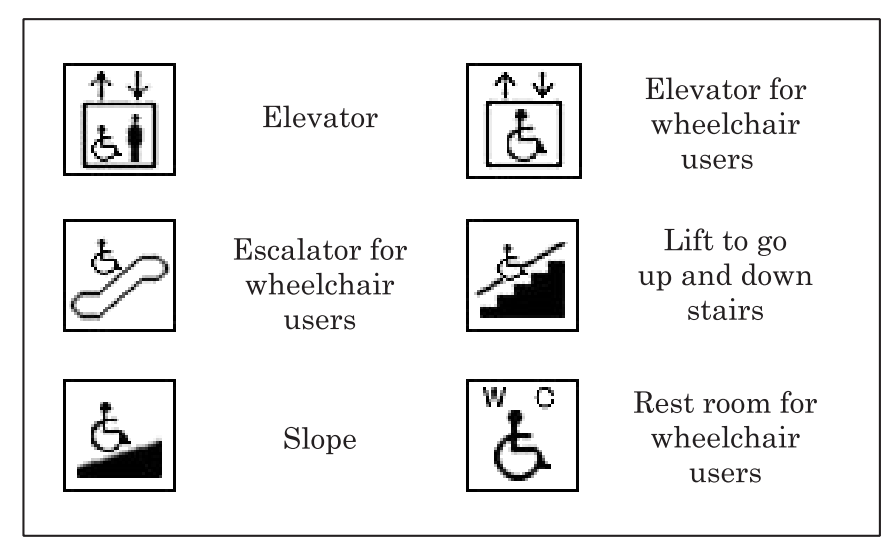

Fig. 2 Symbols used in Internet

page is highly estimated by users. A report shows that most railway operators do not have a full-time manager of Web page and they can not update the contents frequently or spend enough time for updating. Moreover, it takes a lot of time to retrieve information for wheelchair users because the pages including such information are under a number of levels from the top-page. It is necessary to make Web pages easy to retrieve.

As mentioned above, the current information that railway operators provide for wheelchair users is not sufficient. Therefore, they have to depend on the information provided by organizations or groups other than railway operators. Such information is discussed in the following section.

\subsection{Information provided by municipal governments and volunteer groups, etc.}

Public organizations such as municipal governments, social welfare associations, volunteer groups and organizations for the disabled, and disabled in person investigate the actual situation in their local areas regarding the convenience of wheelchair users and provide information. The information provided by them is better than that by railway operators both in quality and quantity, because it is the aim of their activities to provide useful information to wheelchair users travelling by train. Their main ways to provide information are to publish guidebooks and use the Internet.

\section{(1) Guide book}

In Fig. 1, we show a page of a guidebook published by a private volunteer group. It contains various ideas to make it easier to understand the actual situation of the station for wheelchair users. For example, it uses symbols to express the usability of the station for wheelchair users and show the actual situation of facilities at the station more precisely. Some examples of symbols used in general are shown in Fig. 2. Their designs can clearly be understood even by non-handicapped people.

On the other hand, there is a problem that it is difficult for users to gather information about all the places where they want to go, because the information is provided by a number of different organizations. Another problem is that it is difficult to renew the information in guidebooks frequently. Therefore, it is often the case that the information does not reflect the actual situation of stations. Moreover, there is a problem that it is not easy for wheelchair users to know how to get these guidebooks.

\section{(2) Internet}

Among the 16 Web pages we have investigated, two are provided by municipal governments and others by private groups or individuals. Most of them present the information in their local areas, but they contain various ideas to make it easier to understand the actual situation of stations for wheelchair users. They provide not only the information of facilities at stations and on trains, but also the information about concrete routes such as the route from the station entrance to a platform through a ticket gate. Table 3 shows the result of our investigation of the Web pages on the Internet provided by orga-

\section{Table 3 Information provided by providers other than railway} operators (Among 16 Web pages)

\begin{tabular}{|l||c|}
\hline Contents & Number of pages \\
\hline \hline Elevator & 10 \\
\hline Escalator & 10 \\
\hline Lift to go up and down stairs & 2 \\
\hline Rest room for wheelchair users & 9 \\
\hline Rest room with handrail & 2 \\
\hline Slope & 3 \\
\hline Ticket gate for wheelchair users & 1 \\
\hline
\end{tabular}


Table 4 Patterns of the way that providers other than railway operators provide information (Among 16 Web pages)

\begin{tabular}{|l||c|}
\hline Ways to provide information & $\begin{array}{c}\text { Number of } \\
\text { pages }\end{array}$ \\
\hline \hline $\begin{array}{l}\text { Table of facilities for wheelchair users } \\
\text { at each station }\end{array}$ & 6 \\
\hline $\begin{array}{l}\text { Table of stations which have facilities } \\
\text { for wheelchair users }\end{array}$ & 2 \\
\hline Maps of station buildings & 4 \\
\hline Explanation by sentences & 6 \\
\hline
\end{tabular}

nizations other than railway operators. They provide the information in four ways shown in Table 4.

\section{New technique to provide information}

\subsection{Basic concepts}

To solve the problems of the current information services and convey information easily to wheelchair users, a new technique is necessary to realize the following functions for information services.

- Uniformity.

- In consideration of the continuity for movement.

- In consideration of the transfer from one railway to another.

- Using figures and symbols.

For their comfortable travel, each wheelchair user needs the information that depends on his/her own handicap. Then we have studied new techniques by which wheelchair users can obtain necessary information easily and understand the contents intuitively as much as possible.

\subsection{Concrete method}

(1) To provide information on Internet

The Internet is increasingly attracting attention as a tool that enables wheelchair users to collect the information they want on the spot. If the information providers register keywords about their Web pages for the search engine, it makes a way to collect definite information. Moreover, for information providers, it also makes the maintenance of the information easier and enables them to provide the updated information to wheelchair users immediately (Fig. 3).

(2) To provide information by animation

We can provide information by using animation in order to show wheelchair travelers the route from their starting point to their destination. It shows detailed explanation by letters and symbols, so that the users can obtain the information they want at once. Moreover, because wheelchair travelers can experience the route they will use before the travel, it is expected that they feel relaxed when traveling by train.

\subsection{Prototype pages}

According to the basic concept stated above, we have developed a new Web page using animation experimentally. A retrieval process for this Web page is as follows.

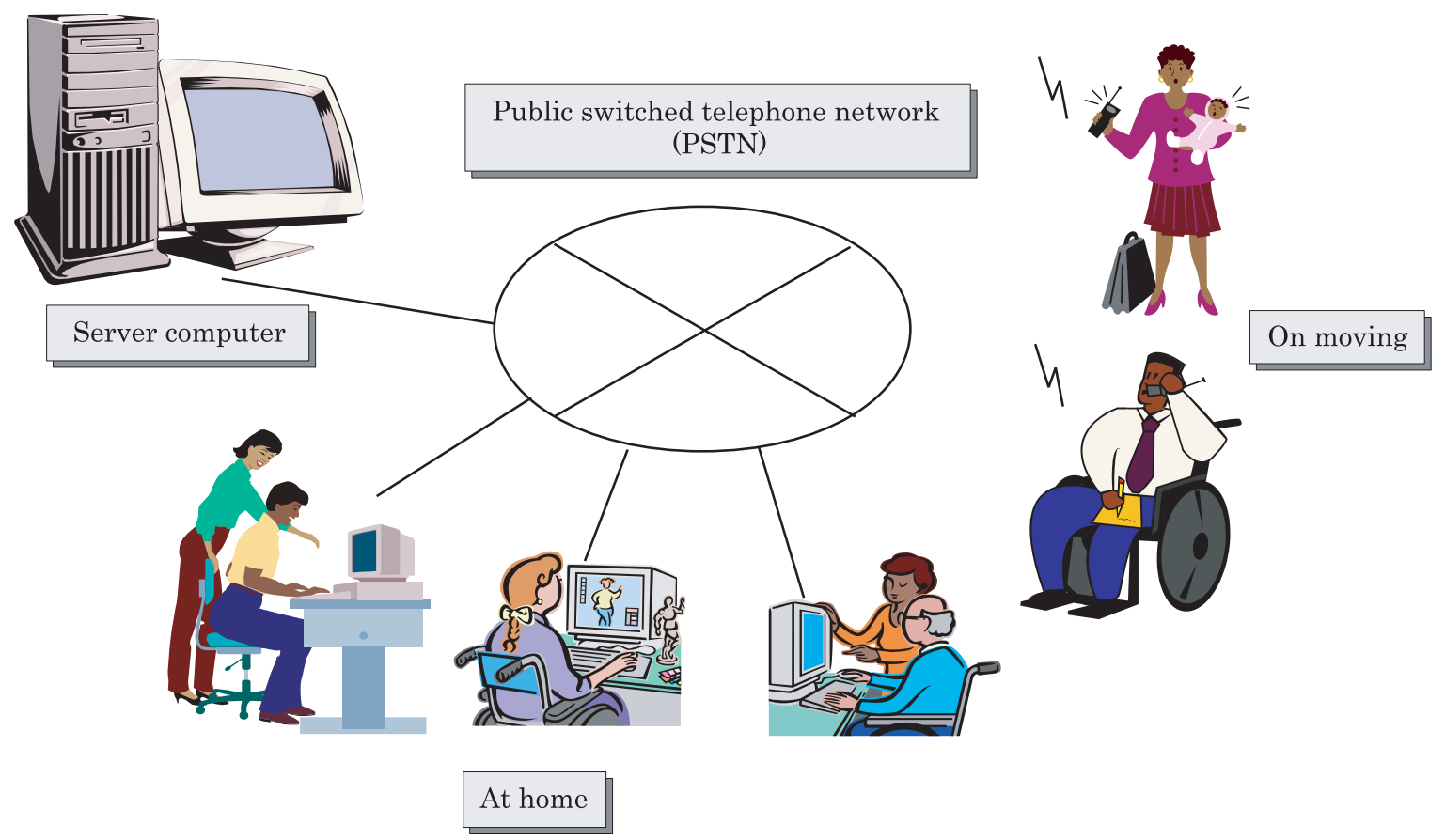

Fig. 3 Image of providing information by Internet 
(1) The user selects the entrance at the departure station and the entrance at the arrival station (Fig. 4 (a)).

(2) At the departure station, the wheelchair traveler in the figure moves in order to show the route from the entrance to a platform and the most convenient position on the platform to transfer trains. When necessary, a detailed explanation is added by using letters such as his/her present location, facilities at the station and whether it needs the help of station staff to use the facility. Figure 4 (b) is a scene of animation in which a wheelchair user moves from the entrance of JR-Kunitachi Station to the point he will get on a train on the platform of Chuo Line for Tokyo.

(3) The wheelchair traveler in the figure moves from the point where he/she gets off a train to the point to get on another train at the transfer station, in order to provide the information about the best route to move and the best door to transfer to the next train. Figure 4 (c) is a scene of animation in which a wheelchair user is moving in the JR-Shinjuku Station us-

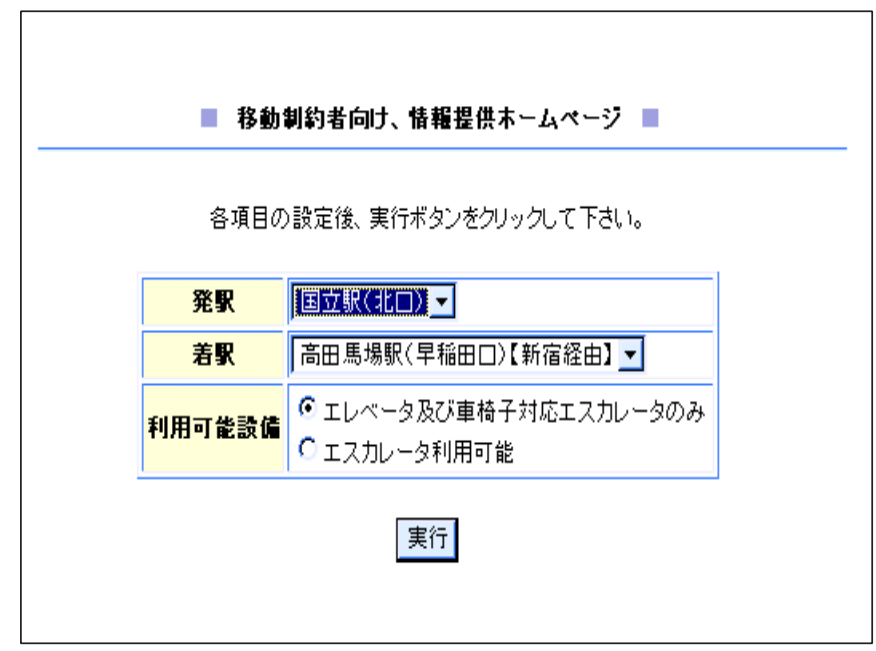

( a )

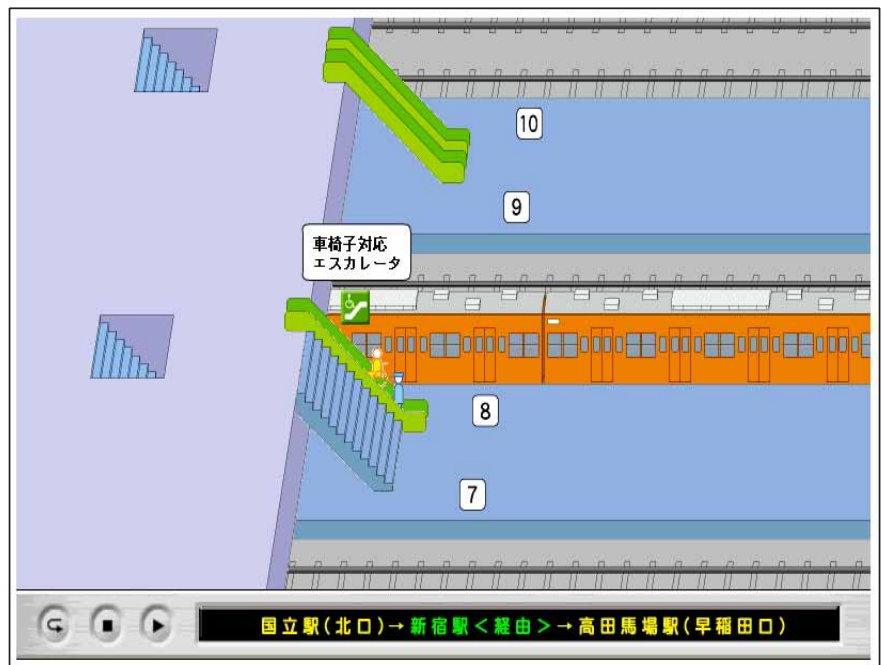

(c) ing an escalator for transfer. To show that, if the help of a station staff is necessary when they use the escalator, a station staff appears in the figure.

(4) At the destination station the wheelchair traveler in the figure moves from the point where he/she gets off the train to the exit of the station for providing the route to move. Figure $4(\mathrm{~d})$ shows a scene in which the wheelchair traveler is moving in the JRTakatanobaba Station by using a lift to go down stairs.

(5) When the user wants to stop or repeat the animation, he will use the button at the bottom of the screen as shown in Fig. 4 (b)-(d).

By using this technique, it is possible to solve most of the problems in the current information services mentioned above. Table 5 shows the result of comparison between this technique and those currently in use. Because the information is provided in the form of image files in this technique, there are the following problems.

- It lacks the mobile property.

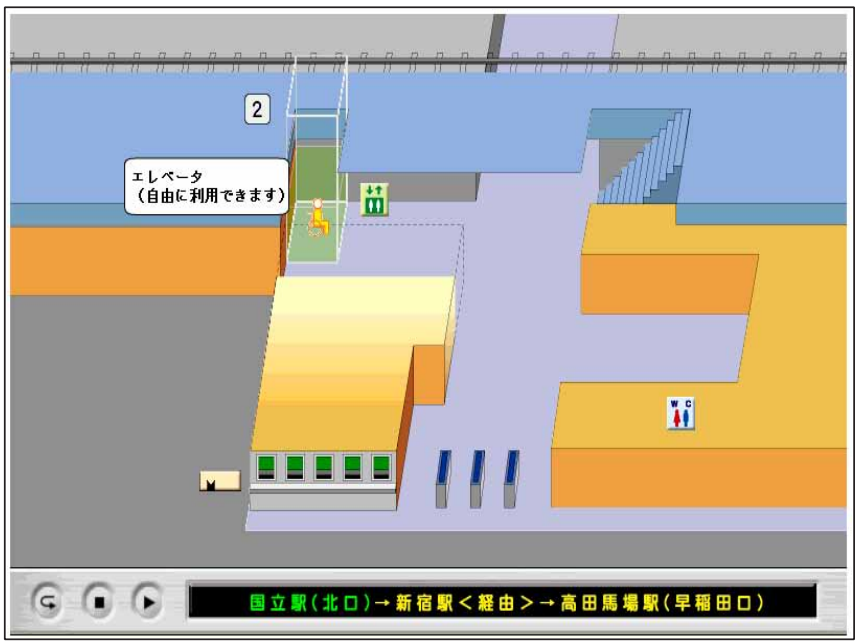

( b )

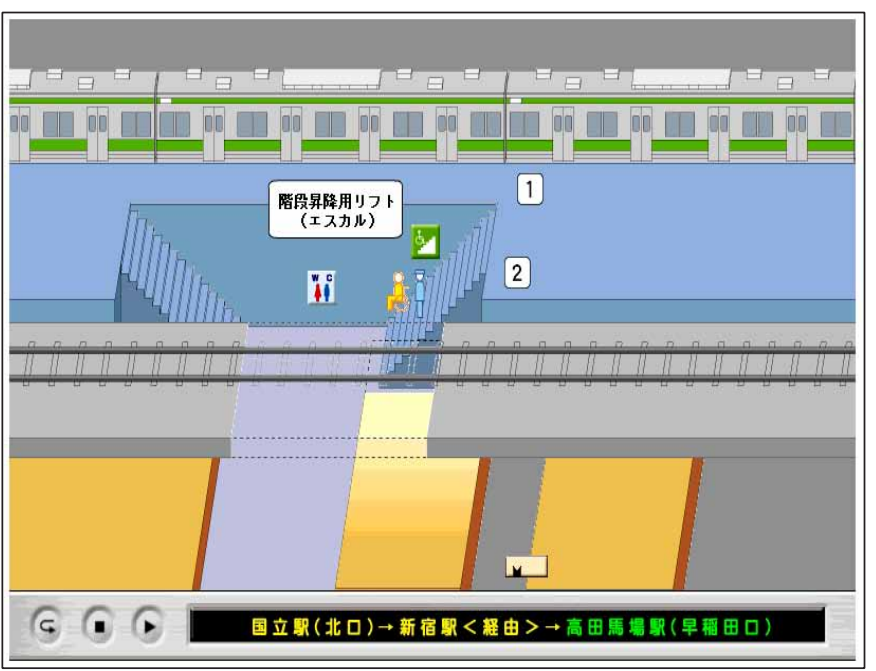

(d)

Fig. 4 Prototype of pages 
Table 5 Result of a comparison between the new technique and those currently in use

\begin{tabular}{|c|c|c|c|c|c|}
\hline & & Guide book & $\begin{array}{l}\text { Internet } \\
\text { table }\end{array}$ & $\begin{array}{l}\text { Internet } \\
\text { map }\end{array}$ & $\begin{array}{l}\text { Internet } \\
\text { animation }\end{array}$ \\
\hline \multicolumn{2}{|l|}{ media } & $\begin{array}{l}\text { letters and } \\
\text { figure }\end{array}$ & table & figure & animation \\
\hline \multirow{2}{*}{$\begin{array}{c}\text { For } \\
\text { providers }\end{array}$} & Amount of works of creation & $\bigcirc$ & $\bigcirc$ & $\triangle$ & $\times$ \\
\hline & Maintainasility & $x$ & $\bigcirc$ & $\triangle$ & $\triangle$ \\
\hline \multirow{6}{*}{ For users } & Property of real time & $x$ & ○ & $\bigcirc$ & $\bigcirc$ \\
\hline & Property of mobility & $\bigcirc$ & $\triangle$ & $x$ & $\times$ \\
\hline & Understandibility & $\bigcirc$ & $x$ & $\triangle$ & $\mathrm{O}$ \\
\hline & Amount of information & $\times$ & $x$ & $\triangle$ & $\bigcirc$ \\
\hline & $\begin{array}{l}\text { Consideration of continuity for } \\
\text { movement }\end{array}$ & $x$ & $x$ & $x$ & $\bigcirc$ \\
\hline & Obtainability & $x$ & $\bigcirc$ & $\bigcirc$ & 0 \\
\hline
\end{tabular}

- It needs a large amount of work for information providers to make and maintain the animation.

It will be possible to solve the problem about the mobile property by using the Third Generation Wireless System such as Wideband Code Division Multiple Access (W-CDMA). For the problem about the amount of work, we have the following solution. In this technique, it is not necessary to gather all the information of geographical data and facilities of station to make the animation. It needs only the information about the area where wheelchair users can move. Therefore, it is possible to limit the amount of information to a minimum, by using divided parts of the animation and a route retrieval function.

\section{Conclusions}

In this paper, we have introduced a new technique which can provide more user-friendly information about the facilities for wheelchair users at stations than the current techniques do. As the information which users need differs from user to user, because it depends on the degree of handicap and the frequency of travel of each user, it is difficult to provide information to satisfy all users. However, we have shown in this paper that the new technique enables wheelchair users to obtain the information they need more easily and understand the contents intuitively. This research and development of the technique were partly assisted by a government subsidy.

\section{References}

1) Dept. of Health and Welfare for Persons with Disabilities, The Ministry of Health and Welfare: "The Investigation of the actual situation of the disabled (in Japanese)," The Ministry of Health and Welfare, 1999

2) Wakakoma Independent Living Information Center : "TOKYO ACCESS GUIDE for Wheelchair Users (in Japanese)," Association on Periodical Publication for Disabled, pp.9-10, 1998

3) The First Section of Investigating and Researching Committee, Congress of Japan Railway Cybernetics : "Report on the investigation and research regarding the system providing information include passengers safety (in Japanese)," Congress of Japan Railway Cybernetics, pp.59-87, 1998

4) Japan Transport Economics Research Center : "Report on the information providing services of public transportation (in Japanese)," Japan Transport Economics Research Center, 1998 